\title{
Limitaciones diagnósticas de las determinaciones inmunohistouuímicas preoperatorias en el linfoma anaplásico de células grandes asociado a implante mamario [LACG-AIM]
}

\section{Diagnostic limitations of preoperative immunohistochemical determinations in breast implant associated anaplastic large cell Iymphoma [BIA-ALCI]}

César CASADO SÁNCHEZ ${ }^{*}$, Vicenta CÓRDOBA CHICOTE**

María Purificación DOMÍNGUEZ FRANJO***, María del Mar VAQUERO PÉREZ ${ }^{* \star * *}$

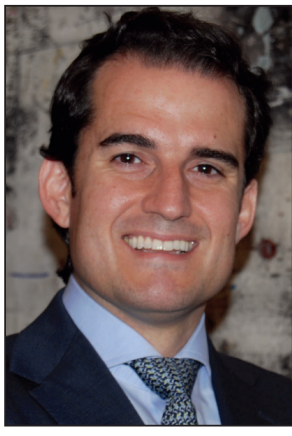

Casado Sánchez C.

\section{Resumen}

Presentamos un caso de linfoma anaplásico de células grandes asociado a implante mamario (LACG-AIM) que debutó como seroma periprotésico unilateral izquierdo de características acelulares en su estudio inicial. Esto limitó la determinación inmunohistoquímica de marcadores CD30 y cinasa del linfoma anaplásico (ALK) y su diagnóstico preoperatorio.

La paciente fue intervenida quirúrgicamente realizándose retirada del implante y capsulectomía completa bilateral. El estudio anatomopatológico de la cápsula periprotésica izquierda mostró un linfoma anaplásico de células grandes.

Dado que algunos casos de LACG-AIM pueden presentarse sin celularidad en el seroma periprotésico, limitando la efectividad de las determinaciones inmunohistoquímicas preoperatorias, en casos de alta sospecha clínica cabría plantearse un tratamiento quirúrgico de forma precoz que iniciase el tratamiento oncológico sin demora y aportase un diagnóstico definitivo.
We present a case of breast implant associated anaplastic large cell lymphoma (BIA-ALCL) that debuted as a left unilateral periprosthetic seroma of acellular features in its initial study. This aspect limited the immunohistochemical determination of CD30 markers and anaplastic lymphoma kinase (ALK) and its preoperative diagnosis.

Patient was operated performing implant removal and bilateral complete capsulectomy. The pathological study of the left periprosthetic capsule showed an anaplastic large cell lymphoma.

Since some cases of BIA-ALCL can occur without cellularity in the periprosthetic seroma, limiting the effectiveness of preoperative immunohistochemical determinations, in cases of high clinical suspicion an early surgical treatment could be considered in order to begin the oncological treatment without delay and providing a definitive diagnosis.
Palabras clave Linfoma anaplásico de células gigantes, Implantes mamarios, Prótesis mamarias, Seroma tardío.

\section{Nivel de evidencia científica Recihido [esta versión] Aceptado}

5 c Diagnóstico

21 julio/2019 20 septiembre/2019

Conflicto de intereses: Los autores declaran no tener ningún interés financiero relacionado con el contenido de este artículo.

Financiación: No hubo fuentes externas de financiación para este trabajo. 
Introducción

El linfoma anaplásico de células grandes asociado a implante mamario (LACG-AIM), entidad cada vez menos desconocida y con presencia global, se ha consolidado pese a su baja incidencia como uno de los principales motivos de preocupación entre los cirujanos plásticos. Prueba de ello son las numerosas referencias bibliográficas existentes en la literatura médica de diversas especialidades que han proliferado en los últimos años. La presentación de Brody en el congreso de la Asociación Americana de Cirugía Plástica en el año 2010, en la que expuso una revisión de la literatura en inglés que recogía $32 \operatorname{casos}^{(1)}$ de los que deducía que la asociación de este especial tipo de linfoma y los implantes mamarios tal vez iba más allá de una mera coincidencia, y la revisión bibliográfica de similares características publicada por Kim un año después, ${ }^{(2)}$ tuvieron continuidad con dos informes de la Food and Drug Administration (FDA) de los EE.UU. en los que se actualizaba la información referente a la seguridad de los implantes mamarios ${ }^{(3)} y$ se informaba de una investigación preliminar en torno a esta patología. ${ }^{(4)}$ Desde entonces se han sucedido distintas publicaciones, incluyendo recientes monografías en las que se aborda el tema desde diferentes puntos de vista: desde la sospecha clínica a las normas para la recogida de muestras, protocolos para pruebas diagnósticas, terapéuticas y seguimiento de las pacientes, estudios epidemiológicos, posibles implicaciones etiopatogénicas, investigaciones a futuro, implicaciones económicas... con la colaboración de los principales conocedores del tema a nivel internacional y con datos proporcionados por las agencias reguladoras de medicamentos y productos sanitarios internacionales. ${ }^{(5,6)}$

Los resultados de diversos estudios definen la asociación más significativa del LACG-AIM con los implantes macrotexturizados, y actualmente estiman una incidencia que varía desde $1 / 2.832^{(7)}$ a $1 / 30.000$ pacientes con implantes mamarios. ${ }^{(5)} \mathrm{La}$ incertidumbre generada en torno a ese tipo de implantes impulsó que organismos sanitarios reguladores, como la Agencia Francesa del Medicamento, prohibiese en abril de 2019 la utilización en Francia de dichos implantes ${ }^{(8)}$, y empresas tan relevantes como Allergan ${ }^{\circledR}$ (Allergan Inc. Dublín, Irlanda) retirasen del mercado mundial sus implantes texturizados Bioce$11 \circledR$ en julio de 2019. ${ }^{(9)}$

En el ámbito iberoamericano, pese a nuestra experiencia más dilatada en el empleo de prótesis texturizadas, llaman la atención los pocos casos publicados, ${ }^{(10,11)}$ posible reflejo del infradiagnóstico de esta patología.

Dado que las formas de presentación del LACG-AIM son heterogéneas ${ }^{(12)}$ y queriendo contribuir a dilucidar los problemas que podemos encontrar frente al diagnóstico de la patología ante los primeros síntomas de sospecha, presentamos la secuencia diagnóstica seguida en un caso que presentó ciertas particularidades que deben hacernos reflexionar respecto a una patología grave.

\section{Caso clínico}

Paciente remitida a la consulta de Cirugía Plástica de su hospital público de referencia, tras valoración a cargo de Atención Primaria y Cirugía General, por presentar aumento de volumen en su mama izquierda de aproximadamente 4 meses de evolución en el contexto de una mamoplastia de aumento practicada 15 años antes (Fig. 1).

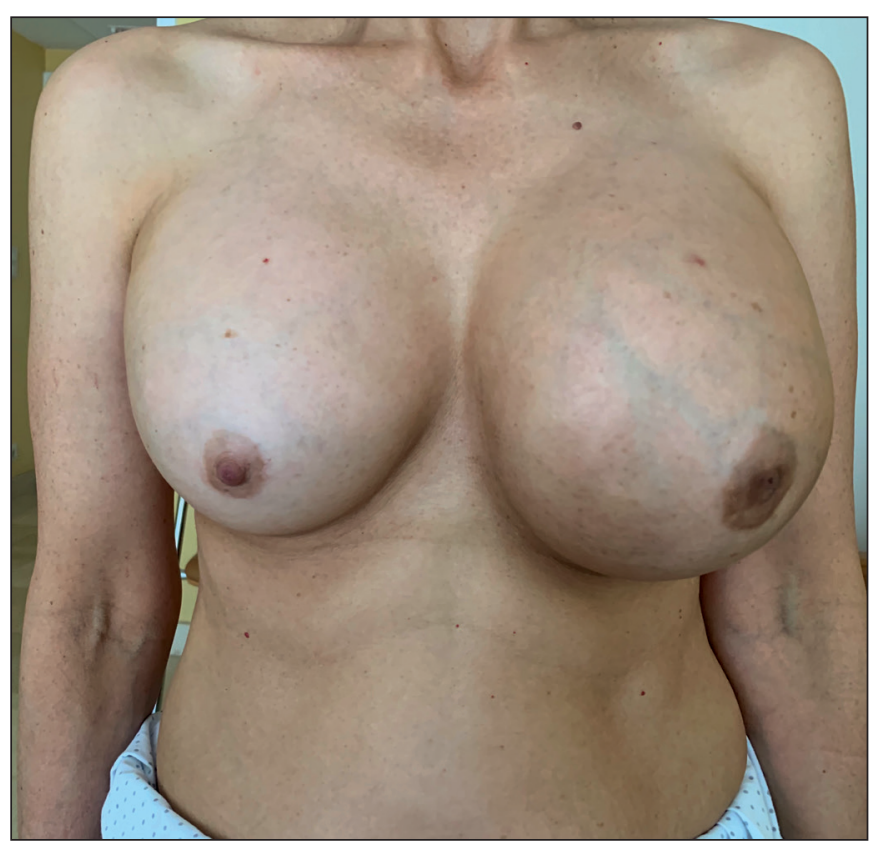

Figura 1. Paciente intervenida de mamoplastia de aumento 15 años antes que acude por incremento de volumen en mama izquierda de 4 meses de evolución.

La paciente había sido intervenida en Colombia, desconocía cualquier característica de los implantes que tenía colocados (nombre del fabricante, tipo de implante, tipo de cobertura o volumen) y del plano de implantación de los mismos. No aportaba informes médicos referentes a aquella intervención y negaba realizarse seguimientos periódicos. No presentaba hábitos tóxicos, antecedentes personales o familiares oncológicos de interés y negaba traumatismos $\mathrm{u}$ otras eventualidades en las mamas de forma previa. Refería como único síntoma molestias continuas en la mama izquierda, sin fiebre u otro signo de interés asociado al aumento de volumen mamario unilateral. A la exploración se apreciaba dicho incremento de tamaño en la mama izquierda, de consistencia dura, sin eritema ni detección de masas u otro signo relevante a la palpación.

Ante la clínica, y contemplando en el diagnóstico diferencial el LACG-AIM, se procedió de acuerdo al 


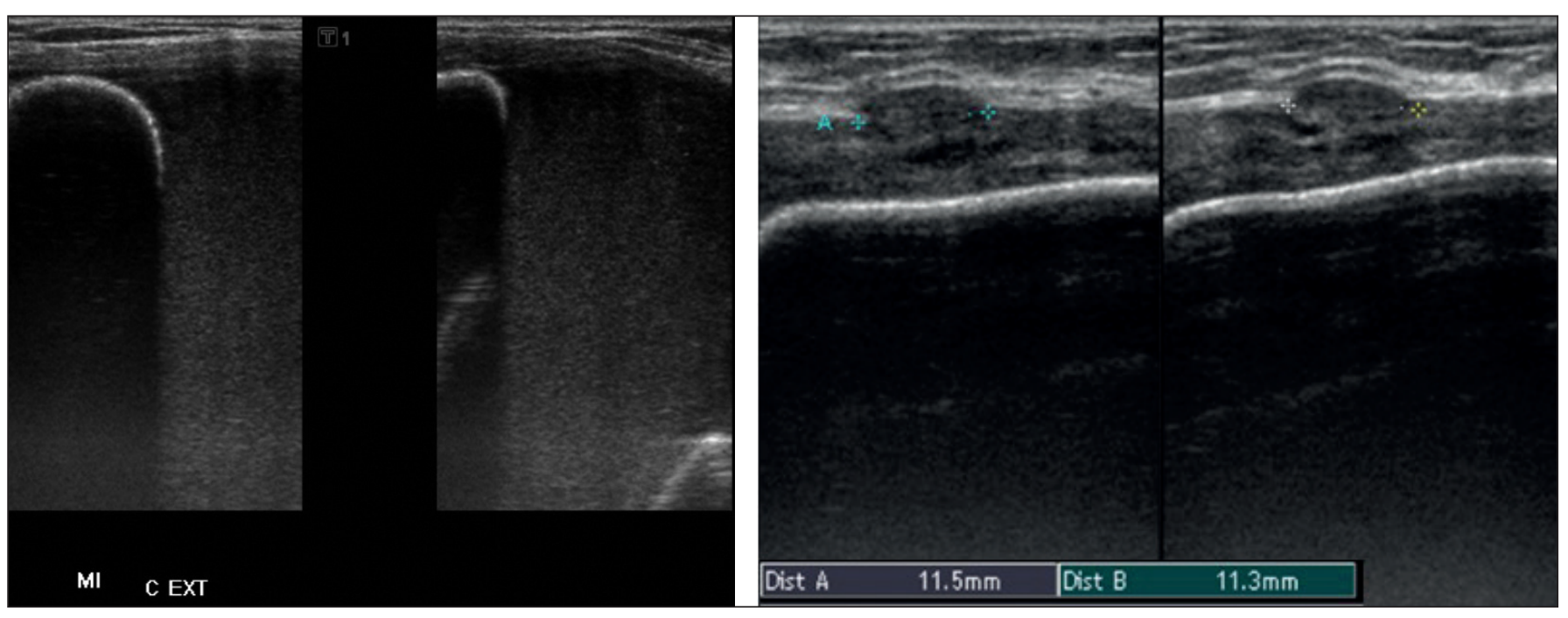

Figura 2. Ecografía mamaria izquierda. A. Abundante líquido periprotésico con ecos móviles en su interior. B. Engrosamiento de la cápsula fibrosa con un área nodular de $1 \mathrm{~cm}$.

protocolo establecido por la Agencia Española de Medicamentos y Productos Sanitarios (AEMPS) ${ }^{(13)}$ para esta patología. Tanto el servicio de Radiología como el de Anatomía Patológica fueron alertados de la sospecha clínica y, conocedores del protocolo, actuaron en consecuencia y con precisión en todo el proceso diagnóstico.

Se realizó inicialmente una ecografía mamaria que no ofreció signos de interés en la mama derecha y objetivó en la mama izquierda presencia de abundante líquido periprotésico con ecos móviles en su interior y áreas de engrosamiento de la cápsula fibrosa protésica (Fig. 2). En la axila izquierda se detectó una adenopatía con engrosamiento cortical, áreas marcadamente hipoecogénicas y flujo doppler en su interior. Se realizó punción aspiración con aguja fina (PAAF) guiada por ecografía del líquido periprotésico, extrayendo $105 \mathrm{cc}$ del mismo, de aspecto seroso denso, con persistencia de abundante cantidad periprotésica no evacuable.
Se enviaron muestras a los servicios de Microbiología que fueron informadas como contenido estéril, y a Anatomía Patológica para estudio citológico. Pese al gran volumen obtenido y el cuidado oportuno en toda su manipulación, el material extraído fue categorizado como proteináceo acelular. La ausencia de células en las muestras del líquido condicionó no hacer el diagnóstico mediante determinaciones inmunohistoquímicas de CD30 y ALK.

Ante estos hallazgos se realizó resonancia magnética (RM) mamaria bilateral que además de confirmar la descripción de la ecografía previa, con engrosamiento irregular de la cápsula fibrosa y una adenopatía axilar (Fig. 3), informó de prótesis mamarias sin signos de rotura intra ni extracapsular.

Se realizó biopsia con aguja gruesa (BAG) guiada por ecografía de una región de engrosamiento nodular de $1 \mathrm{~cm}$ en el cuadrante súpero interno de la cápsula protésica de la mama izquierda, con resultado anatomopatológi-

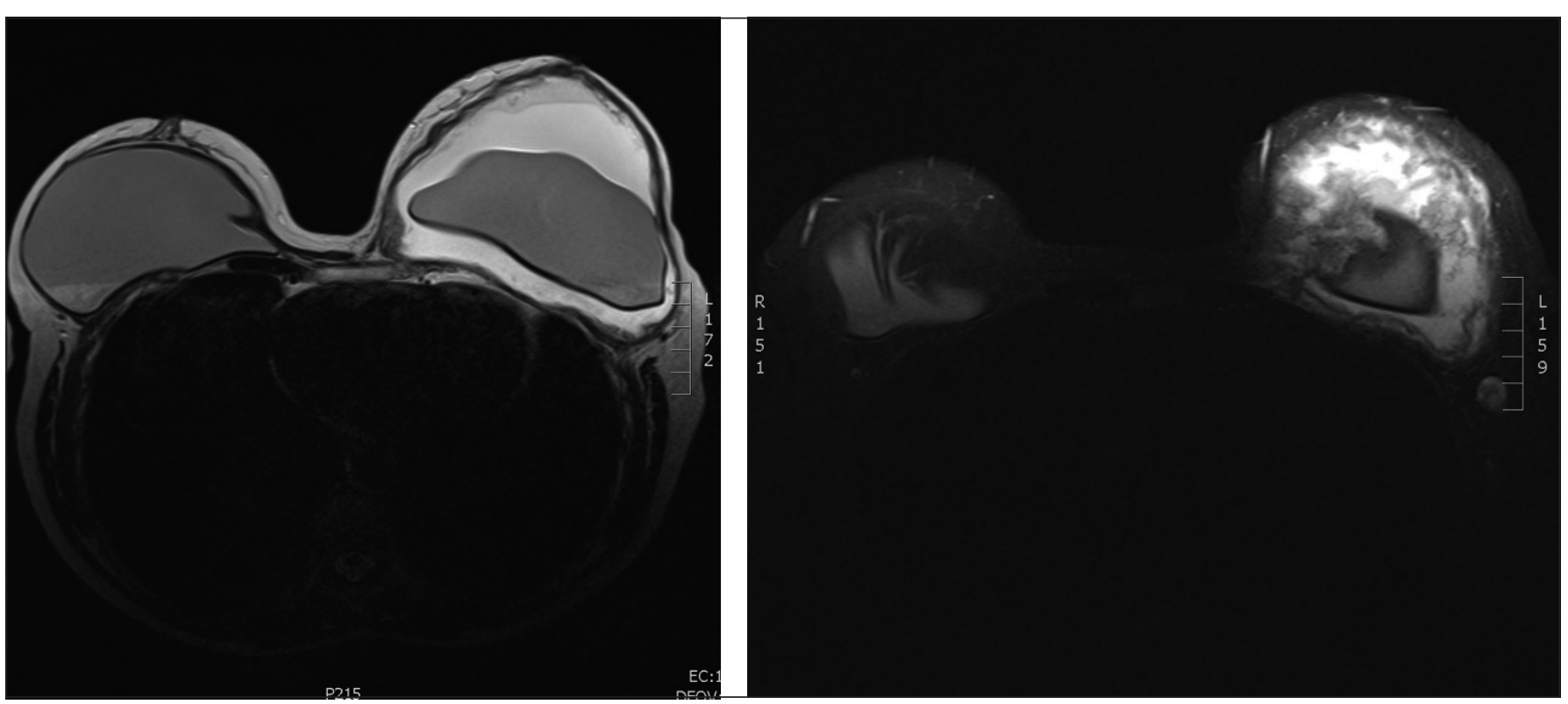

Figura 3. Resonancia magnética nuclear, plano coronal. A. Secuencia potenciada en T2. Líquido periprotésico con engrosamiento irregular de la cápsula fibrosa. B. Secuencia potenciada en T2 con saturación de la grasa. Irregularidad de la cápsula fibrosa y adenopatía aumentada de tamaño. 
co de área necrótica con celularidad no viable y músculo estriado con inflamación crónica inespecífica. Dicha ausencia de celularidad viable igualmente limitó la realización de técnicas inmunohistoquímicas. Así mismo, se efectuó una BAG guiada por ecografía de la adenopatía axilar izquierda con resultado de adenopatía reactiva.

Ante la falta de confirmación citológica o histológica de LACG-AIM u otros signos radiológicos que orientasen hacia un proceso maligno, la paciente fue informada de los resultados y, teniendo en cuenta la posibilidad de que se tratase de un seroma tardío en el contexto de una complicación de prótesis mamarias implantadas por motivos estéticos, se le aconsejó valoración en el entorno de la sanidad privada, de acuerdo a la normativa sanitaria de nuestro centro hospitalario.

La paciente acudió a consulta de ámbito privado, donde se le planteó intervención quirúrgica para retirada bilateral de los implantes mamarios y capsulectomía completa a través de abordaje periareolar y vertical, sin colocación de nuevas prótesis mientras no se obtuviese un diagnóstico definitivo del cuadro. La cirugía se realizó bajo anestesia general, con idénticas condiciones a las que se hubiese procedido en caso de LACG-AIM conocido de forma preoperatoria. Transcurrió sin incidencias reseñables en la mama derecha, realizándose capsulectomía y retirada de la prótesis mamaria que resultó ser de cobertura macrotexturizada y ubicada en plano subpectoral. En la mama izquierda, donde también se encontró una prótesis macrotexturizada subpectoral, se extrajeron además $300 \mathrm{cc}$ de material seroso denso, no purulento ni hemorrágico (Fig. 4), y se apreció intensa atrofia del parénquima mamario y del músculo pectoral mayor e intenso infiltrado de la musculatura intercostal por parte

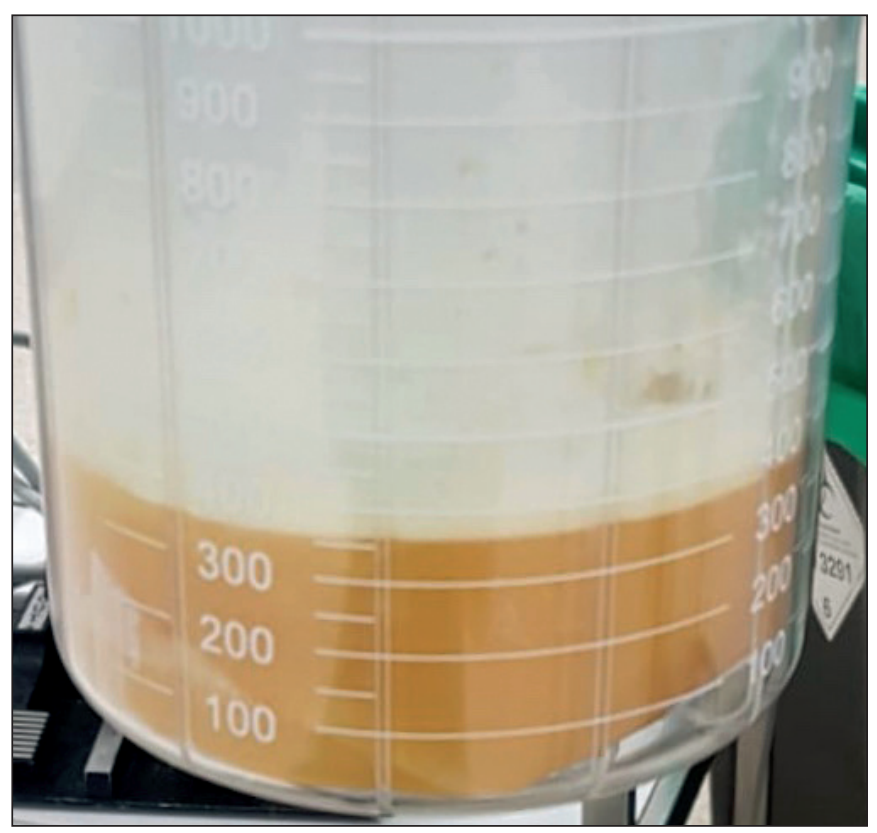

Figura 4. Extracción intraoperatoria de $300 \mathrm{cc}$ de material de la mama izquierda, de aspecto seroso, denso, no purulento ni hemorrágico.

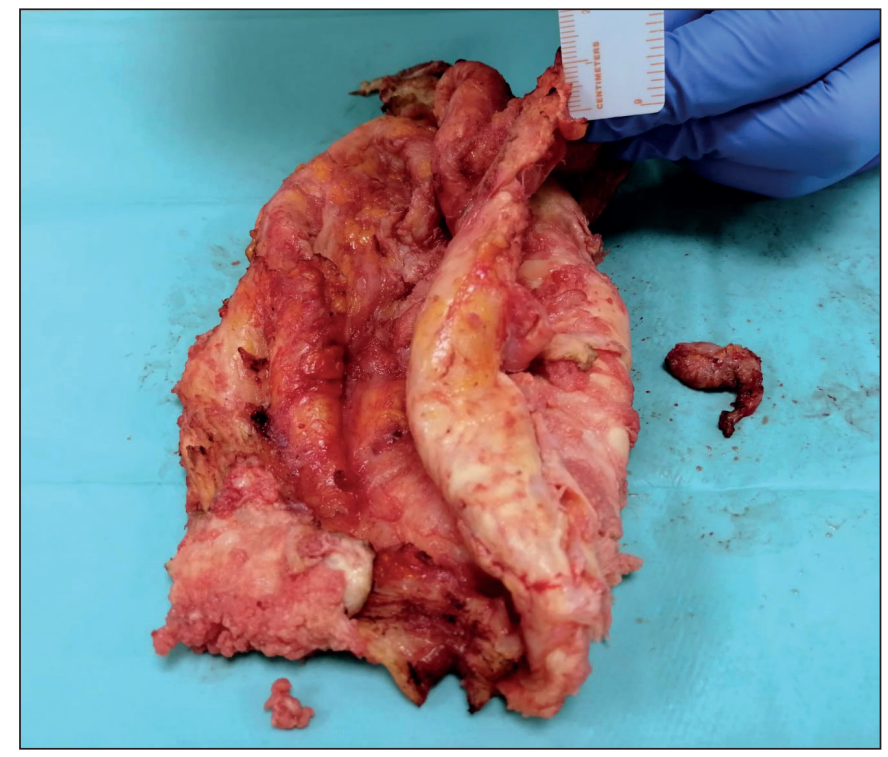

Figura 5. Imagen de la cápsula periprotésica desarrollada en la mama izquierda, donde se observa un grosor relevante.

de una cápsula periprotésica gruesa (Fig. 5), con su cara interna o protésica de aspecto blanquecino, en la que se desarrollaban pequeñas tumoraciones (Fig. 6). Se extirpó parcialmente la musculatura intercostal hasta la pleura parietal en distintos espacios intercostales, dada la intensa infiltración que presentaba por parte de la cápsula periprotésica. Dicha infiltración no permitió asegurar que, pese a realizar una capsulectomía completa que incluyó amplios segmentos de la musculatura intercostal, todo el material que infiltraba dicho músculo fuese extirpado completamente. Ninguna de las prótesis mamarias estaba rota, en consonancia con los hallazgos de la RM. Se realizó lavado de los bolsillos, hemostasia, cierre por planos y colocación de drenajes aspirativos que se mantuvieron durante 3 días en el postoperatorio. La paciente fue dada de alta sin incidencias a las 24 horas de la intervención.

El material seroso fue enviado a análisis de microbiología para detección de bacterias, micobacterias y hon-

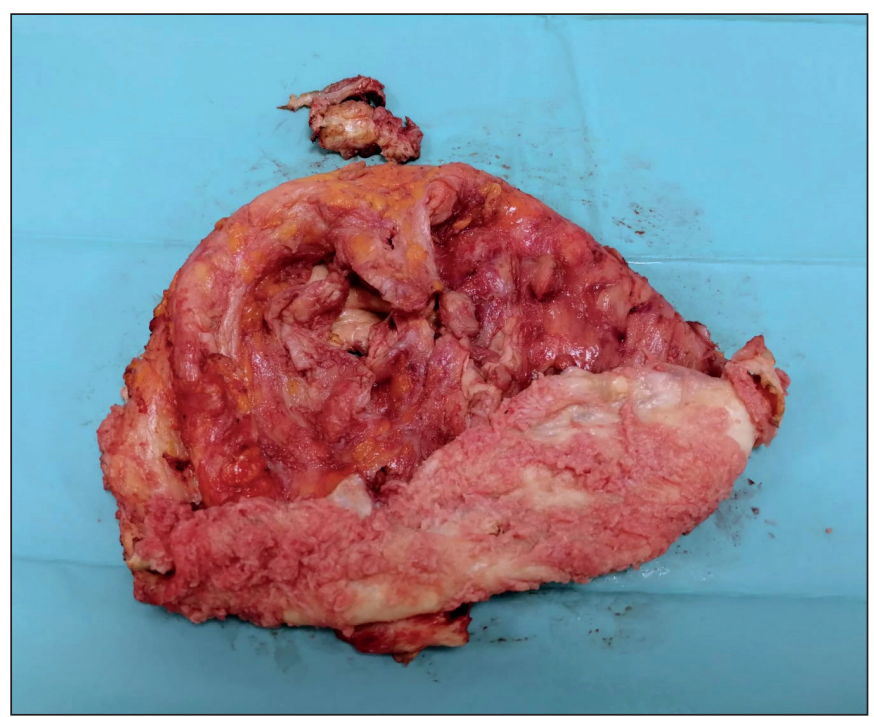

Figura 6. Imagen de la cápsula periprotésica desarrollada en la mama izquierda: cara interna o protésica con aspecto blanquecino y pequeñas tumoraciones. 


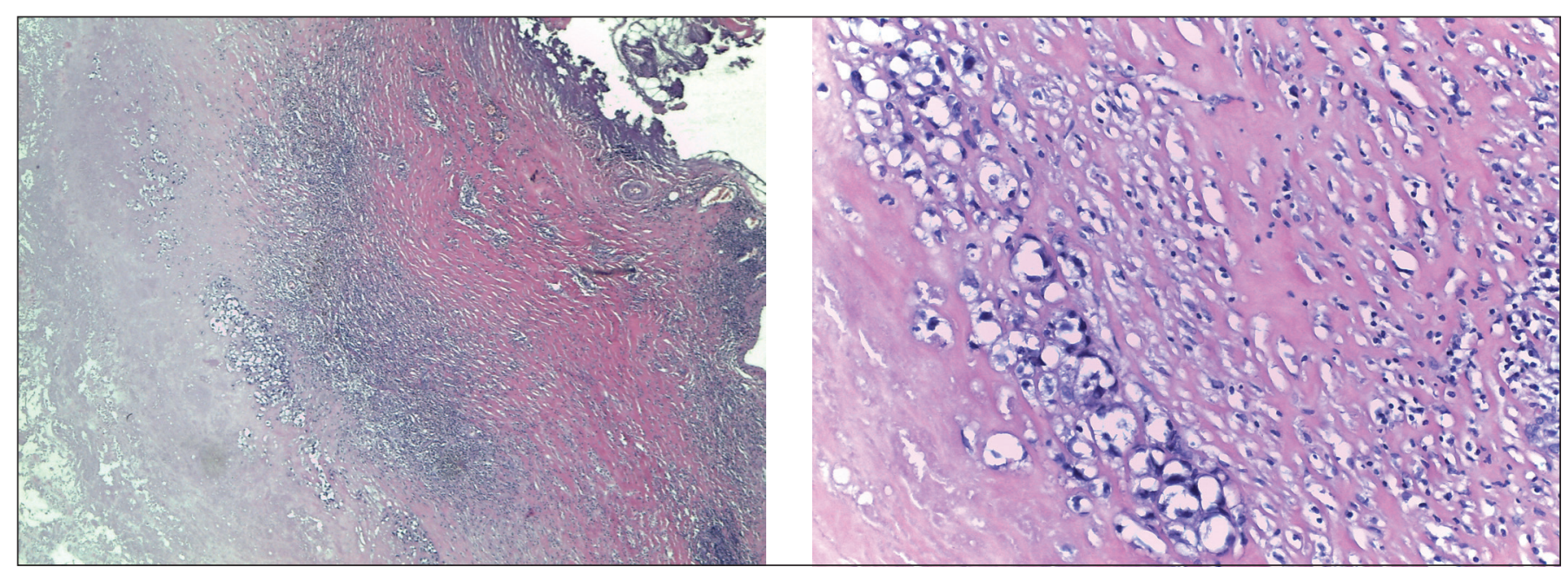

Figura 7. Imágenes histológicas. A. Panorámica que muestra la distribución del tumor en el tejido fibroso periprotésico (H/E 4X). B. Detalle de células grandes pleomórficas (H/E 20X).

gos, el cual presentó resultados estériles. Las cápsulas periprotésicas fueron enviadas a estudio anatomopatológico con resultado de cápsula periprotésica sin signos de malignidad en mama derecha y cápsula periprotésica con linfoma de células grandes T anaplásico CD30+ ALKen mama izquierda; los cortes histológicos mostraban una proliferación de células grandes de amplio citoplasma, con fenotipo CD20-, CD3+ focal, CD4+, CD30+, GRANZIMA+, ALK- (Fig. 7 y 8).

Una vez confirmado el diagnóstico, se siguieron las pautas de notificación obligatoria para este tipo de patología a la AEMPS, notificación a la Sociedad Española de Cirugía Plástica, Reparadora y Estética (SECPRE), además de contactar con el fabricante del implante (Silimed ${ }^{\circledR}$, Silimed - Industria Ltda. Implants, Brasil) por mediación de la AEMPS.

La paciente fue valorada por el Comité de Patología Mamaria del hospital público de referencia y remitida al Servicio de Hematología para seguimiento por parte de la Unidad de Hematología Oncológica. Se realizó estudio de extensión mediante RM y tomografía por emisión de positrones (PET-TAC). Ninguna de las dos exploraciones demostró afectación sistémica y la RM objetivó, además de los cambios postquirúrgicos locales, una disminución relevante de la adenopatía en concordancia con el carácter reactivo objetivado en la BAG. Se solici- tó un nuevo PET-TAC a los 3 meses de la intervención, una vez superado el proceso inflamatorio vinculado a la intervención, que no evidenció tejido tumoral viable. Se realizó además una biopsia por aspiración de médula ósea que no mostró signos de interés.

En esta situación y dada la afectación extracapsular con infiltración de pared costal objetivada en la intervención quirúrgica, la paciente fue diagnosticada como estadio IIA, T4 N0 M0 ${ }^{(14)}$ con indicación de iniciar tratamiento sistémico, empleándose brentuximab vedotin asociando la pauta CHP (ciclofosfamida, doxorrubicina y prednisona, sin incluir vincristina de la pauta $\mathrm{CHOP}$ ). Brentuximab es un tipo de terapia dirigida, conjugado de anticuerpo y de fármaco, aprobado para el tratamiento de pacientes con linfoma de Hodgkin y también para algunos tipos de linfomas anaplásicos de células grandes, como el presente caso. El componente anticuerpo del tratamiento se fija a la proteína CD30 en la superficie de la célula cancerosa, liberándose el fármaco en ese momento de forma intracelular y causando la destrucción celular. Brentuximab vedotin también se ha utilizado con éxito en el tratamiento de LACG-AIM irresecable. ${ }^{(15)}$

La paciente se mantiene en revisiones periódicas a cargo de los Servicios de Hematología y Cirugía Plástica.

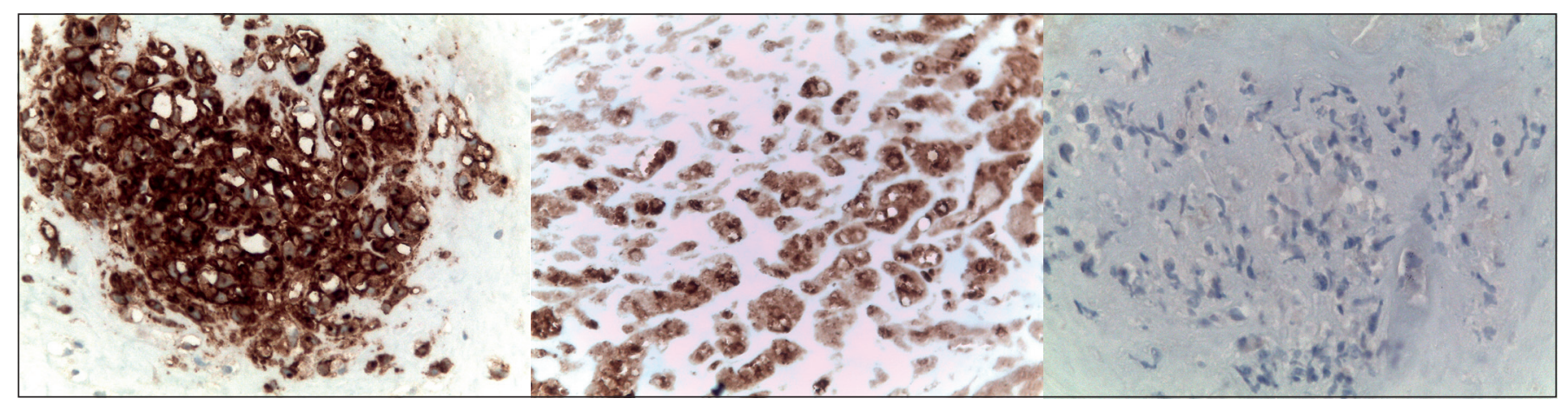

Figura 8. Imágenes diagnósticas de los biomarcadores. A. CD30 positividad intensa (400X). B. CD4 positivo (400X). C. ALK negativo (400X). 
Discusión

Pese a un conocimiento cada día mayor del LACG-AIM, aún no conocemos su verdadera etiología ni todas sus formas de presentación. Los protocolos diagnósticos publicados ${ }^{(9,16)}$ detallan el proceso adecuado a seguir en caso de sospecha clínica, pero considerando que se trata de una entidad potencialmente letal aún no bien conocida, no debemos subestimar su incidencia u obviarla al plantear un diagnóstico diferencial ya que como en todo cáncer, el tratamiento precoz es relevante, tal y como sugieren los casos de fallecimiento vinculados a esta enfermedad. Es decir, pese a dichos protocolos, la capacidad clínica del profesional para considerar esta patología debe ser considerada.

De acuerdo a dichos protocolos, la primera prueba que se debe solicitar en caso de sospecha de LACG-AIM es una PAAF guiada con ecografía y la determinación de CD30 y ALK en el líquido extraído. El LACG-AIM es por definición CD30+ y ALK-, pero dichas características, de forma aislada o combinadas, no son patognomónicas de la enfermedad. Distintos factores, como la falta de descamación de la masa tumoral de la propia cápsula infiltrada por el linfoma o una muestra demasiado escasa o mal conservada, pueden inducir en algunos casos a diagnósticos erróneos, dado que la muestra podría carecer de material citológico para realizar las determinaciones inmunohistoquímicas. Considerando que dichas determinaciones no se realizan de forma rutinaria, el anatomopatólogo debe ser informado de la sospecha clínica para llevar a cabo los estudios pertinentes para esta enfermedad.

Es crucial una cuidadosa obtención y procesado de la muestra de líquido periprotésico extraído ${ }^{(17)}$ para obtener un diagnóstico inmunohistoquímico correcto. Debe remitirse a estudio citológico un volumen amplio del líquido (idealmente mayor de $20 \mathrm{cc}$ ) para su posterior procesado, que debe realizarse de forma inmediata para evitar la degradación celular por múltiples circunstancias (variaciones del $\mathrm{pH}$, actividad enzimática, etc.). Si ese procesado inmediato no fuese posible, la muestra debe conservarse en frío hasta un máximo de 24 horas o añadir formol al $10 \%$ al líquido para posibilitar su procesado como bloque celular, preservando las proteínas y ácidos nucleicos para realizar técnicas inmunohistoquímicas y moleculares. Si fuese posible obtener abundante líquido, se debe enviar además una muestra a estudio microbiológico.

Respecto la presencia de células tumorales en el seroma, debemos señalar que dichas células pueden localizarse en ese seroma a nivel intracapsular o limitarse a afectar al tejido fibroso capsular periprotésico, como en el caso que presentamos, en ocasiones formando una masa. Por ello, dado que las células tumorales se limitaron al tejido fibroso capsular, el estudio citológico inicial del seroma de nuestra paciente no fue diagnóstico. ${ }^{(18)}$

En relación a los resultados ofrecidos por el estudio histológico de la adenopatía, es interesante conocer que, en el contexto de esta enfermedad, algunos autores recomiendan realizar biopsia quirúrgica abierta ya que pueden obtenerse resultados falsos negativos en las BAG. Pero cabe también recordar que los falsos negativos son relativamente frecuentes tanto en las PAAF como en las BAG en los casos de linfomas de bajo grado, y sin embargo una BAG de una adenopatía resulta altamente sensible y específica para linfomas de alto grado, como es el caso de los LACG-AIM.

Existen diversas formas de presentación del LACG-AIM, con una media de 9.9 años desde la colocación de los implantes mamarios hasta la aparición de los síntomas ${ }^{(12)}$ y un rango desde los 2 meses (considerando que ese caso se trató de una paciente sometida a un recambio protésico) hasta los 28 años, que incluiría los 15 años del presente caso. El seroma periprotésico unilateral es la manifestación más frecuente, aunque la eventual presentación como una masa palpable, pese a ser infrecuente, puede facilitar el diagnóstico. ${ }^{(1)}$ Es por ello importante que el radiólogo realice una búsqueda minuciosa de posibles tumoraciones en estas pacientes así como un estudio de las axilas, siendo la ecografía la técnica radiológica de elección para la primera exploración.

Considerando la gran variabilidad descrita para esta patología y ante la existencia de casos como el nuestro en el que la presentación inicial con acelularidad del líquido periprotésico y células necróticas no viables en la biopsia con aguja gruesa de la cápsula limitan el diagnóstico preoperatorio, no debería subestimarse el criterio clínico del profesional ante una historia clínica sospechosa de LACG-AIM (paciente portadora de implantes con más de un año de postoperatorio, con aumento de volumen mamario unilateral espontáneo y sin signos de infección). Por ello, en estas circunstancias, nuestra actitud terapéutica quirúrgica es idéntica a la que realizaríamos ante un LACG-AIM confirmado de forma preoperatoria, ${ }^{(19)}$ planificando la intervención antes de acudir a quirófano y efectuando una retirada de prótesis con capsulectomía completa, evitando en lo posible la apertura de dicha cápsula periprotésica (Fig. 9) y no implantando una nueva prótesis. En el caso que describimos, dado el excesivo grosor de la cápsula y su adherencia firme a todos los planos, no fue posible su extracción en monobloque como hubiéramos deseado. La actitud de no colocar nuevas prótesis en presentaciones clínicas simi- 


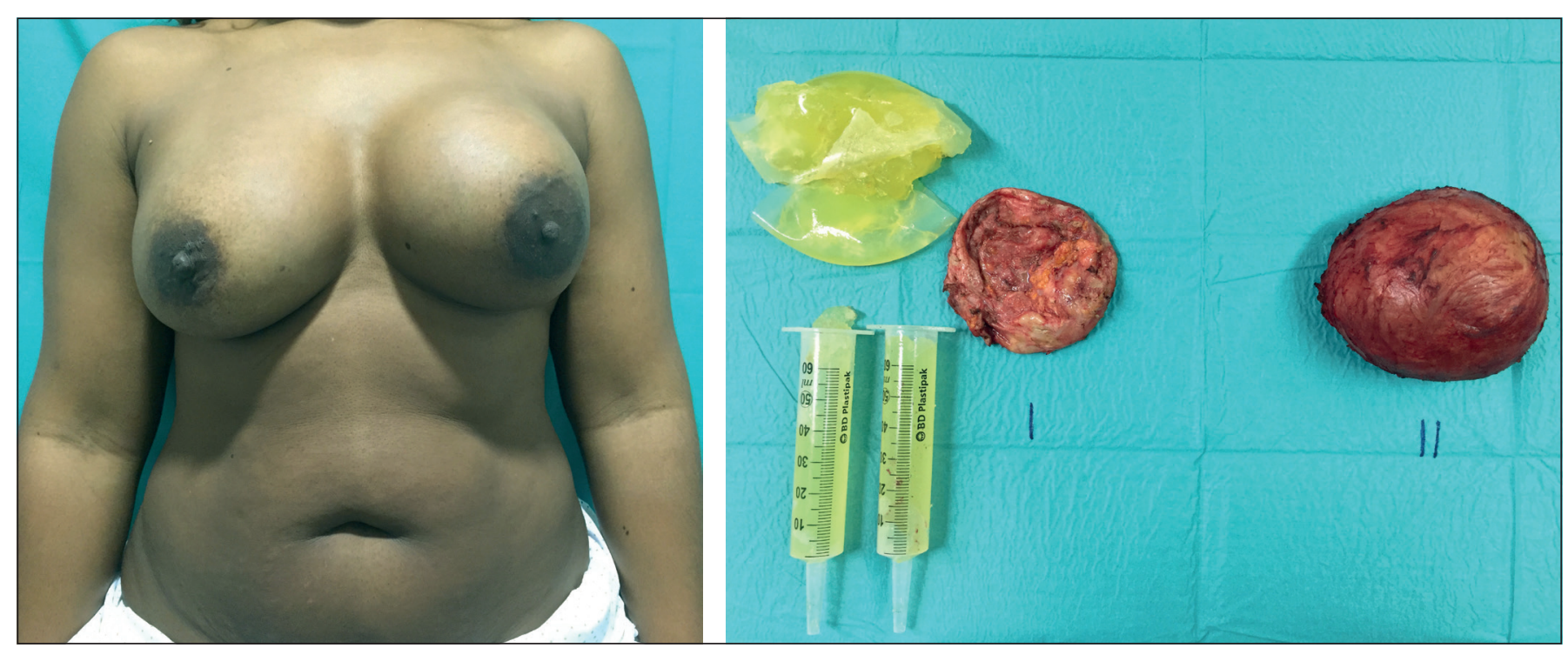

Figura 9. Paciente con historia clínica sospechosa de LACG-AIM, portadora de implantes de más de 1 año de evolución. A. Aumento de volumen unilateral izquierdo. B. Pese a un estudio inmunohistoquímico preoperatorio que no orientó a LACG-AIM se realizó cirugía idéntica a la aconsejada en esos casos, incluyendo retirada protésica con capsulectomía completa y evitando la apertura de la cápsula. En la mama derecha se objetivó rotura protésica.

lares, independientemente de la etiología oncológica o no, redunda en el beneficio de las pacientes, simplifica una recuperación postoperatoria sin incidencias y permite una toma de decisiones respecto a un nuevo implante en una situación más apropiada.

Las pacientes diagnosticadas de LACG-AIM deben ser atendidas por parte de comités multidisciplinares con experiencia en tratamiento oncológico, en centros con servicios de Hematología con experiencia en el tratamiento y seguimiento de linfomas. En nuestro caso, las reuniones de dicho comité tienen carácter semanal y en ellas se presentan todos los pacientes diagnosticados de cáncer de mama u otra patología mamaria relevante, tomándose las decisiones referentes a los procedimientos diagnósticos y terapéuticos a seguir de forma consensuada tras debate entre los miembros del comité. Como especialistas conocedores de la realidad de los implantes mamarios, la participación de los cirujanos plásticos en los comités de patología mamaria, y en ese entorno, la comunicación constante con radiólogos y anatomopatólogos, es clave para que los procesos sean realizados de la mejor manera posible. Es importante la concienciación de todo el personal sanitario respecto al manejo del LACG-AIM para evitar errores diagnósticos y terapéuticos, como no emplear determinaciones inmunohistoquímicas, hacer una mala selección de las técnicas radiológicas, una manipulación deficiente de las muestras, ejecutar intervenciones quirúrgicas erróneas o no realizar un muestreo adecuado de las piezas quirúrgicas en su estudio anatomopatológico.

Desde la aparición de los implantes mamarios de cubierta texturizada en 1968, la supuesta reducción de la contractura capsular que asociarían continúa siendo una controversia solo aplicable en casos de aumento sub- glandular. ${ }^{(20)}$ Actualmente, un gran número de cirujanos plásticos, antiguos defensores de aquel concepto que proponía una menor contractura capsular con los implantes texturizados, han abandonado el empleo de la macrotexturización del tipo de la que portaba nuestra paciente, más relacionados según parece con el LACG-AIM.(12) Además, por parte de las empresas fabricantes y de las agencias sanitarias parece haber una tendencia a realizar modificaciones tanto en los procesos de fabricación y texturización de los implantes, como en las normativas reguladoras de estándares de nomenclatura para los mismos. ${ }^{(21)}$

La paciente de nuestro caso no presentaba informes ni documentación identificativa de los implantes que portaba por lo que solo se pudo detectar la marca, volumen y tipo de cubierta durante la cirugía, siendo esos datos compatibles con los reportados en la mayoría de las publicaciones, ${ }^{(5,7)}$ pero no fue posible obtener datos referentes al número de serie y otros detalles de interés de dichos implantes. Esta realidad demasiado frecuente, que dificulta entre otras cosas la recogida real de datos de los casos, debe hacernos reflexionar.

En el sistema sanitario público español se valora clínicamente a muchas pacientes que acuden por complicaciones derivadas de intervenciones realizadas con motivos estéticos en el entorno de la sanidad privada, realizadas tanto en España como en otros países, incluidas aquellas relacionadas con implantes mamarios. La mayoría de estas pacientes acuden sin informes referentes a la intervención a la que se sometieron en su día o datos que puedan orientar su seguimiento. La asistencia de estas pacientes se dirige a obtener un diagnóstico preciso de una enfermedad y realizar un tratamiento quirúrgico en caso estrictamente necesario. En nuestro 
centro hospitalario, en ausencia de criterios diagnósticos que comprometan la salud, una vez valoradas y estabilizado el cuadro clínico son remitidas para atención en el ámbito de la sanidad privada. La existencia de esta relativamente nueva entidad que es el LACG-AIM, con posibilidad de presentación clínica como la descrita, también nos hace plantear la necesidad de asegurar un diagnóstico definitivo en casos de alta sospecha clínica, aunque el resto de criterios objetivos no hayan aportado resultados concluyentes en las exploraciones preoperatorias. Los avances en investigación en la búsqueda de otras pruebas complementarias o incluso alternativas a la inmunohistoquímica para el diagnóstico etiológico en seromas tardíos, como el CD30 ELISA, ${ }^{(22)}$ podrían darnos soluciones eficaces, eficientes y efectivas en esa etapa preoperatoria.

Por último, destacar la obligación legal de notificar todos los casos de LACG-AIM diagnosticados en España a la Agencia Española del Medicamento y Productos Sanitarios (AEMPS) y la posibilidad de su notificación a la Sociedad Española de Cirugía Plástica, Reparadora y Estética (SECPRE). Cabe destacar que la AEMPS ha simplificado notablemente la notificación de incidentes con productos sanitarios a través de su portal de vigilancia de productos sanitarios, pudiendo efectuarse ágilmente de forma telemática e incluir imágenes o informes del caso (https://notificaps.aemps.es/enviotelematico/ notificaps/notifica/inicio.do). Asimismo, la SECPRE designó en 2015 una comisión interna de seguimiento del LACG-AIM que permanece en todo momento actualizada de forma activa y asesora a sus miembros en el conocimiento de esta entidad, a la vez que habilitó una dirección de correo electrónico donde los especialistas en Cirugía Plástica españoles pueden notificar sus nuevos casos (linfomas@secpre.org).

\section{Conclusiones}

El estudio citológico y las determinaciones inmunohistoquímicas en el líquido periprotésico en casos de seroma tardío o recidivante en pacientes portadoras de implantes mamarios puede resultar insuficiente como orientación diagnóstica preoperatoria en determinados casos de LACG-AIM. Entre los motivos destaca la ausencia de descamación celular del tumor, que limitaría realizar dichas determinaciones.

Con el conocimiento actual de la enfermedad, el criterio profesional continúa siendo muy relevante. Si la sospecha clínica es elevada, en caso de aparición de seroma tardío o recidivante en paciente portadora de implante mamario y en ausencia de otra etiología confirmada, cabría plantearse de inicio una estrategia de tratamien- to quirúrgico similar al del LACG-AIM diagnosticado, incluyendo la retirada del implante y la capsulectomía completa, aún en ausencia de celularidad positiva en la muestra diagnóstica de líquido de seroma, dado que el tratamiento más eficaz de esta patología consiste en realizar esta intervención de la forma más precoz posible tras la aparición de los síntomas.

\section{Dirección del autor}

Dr. César Casado Sánchez

Servicio de Cirugía Plástica y Reparadora

Hospital Universitario La Paz

Paseo de la Castellana 261

28046 Madrid, España

Correo electrónico: doctorcasado@gmail.com

Bibliografía

1. Brody G. T. Cells non Hodking anaplastic lymphoma associated with one style of breast implants. American Society of Plastic Surgeons Annual Conference, March 20-23, 2010 Scientific Session IX: Breast B, Oral communication and Abstract 42.

2. Kim B, Roth C, Chung KC, Young VL, van Busum K, Schnyer C, Mattke S. Anaplastic large cell lymphoma and breast implants: a systematic review. Plast Reconstr Surg. 2011;127(6):2141-2150.

3. FDA Update on the Safety of Silicone Gel-Filled Breast Implants. June 2011, Center for Devices and Radiological Health U.S. Food and Drug Administration.

4. Anaplastic Large Cell Limphoma (ALCL) in women with breast implants: preliminary FDA Findings and Analyses. June 2011, Center for Devices and Radiological Health U.S. Food and Drug Administration.

5. Rohrich RJ. et al. A Review of Breast Implant-Associated Anaplastic Large Cell Lymphoma. Plast Reconstr Surg. 2019;143(3S):S1-S81.

6. Clemens MW. et al. Current Controversies in Breast Implant-Associated Anaplastic Large Cell Lymphoma. Aesthet Surg J. 2019 Jan 31;39(Supplement_1):S1-S65.

7. Collett DJ, Rakhorst H, Lennox P, Magnusson M, Cooter R, Deva AK. Current risk estimate of Breast Implant - Associated Anaplastic Large Cell Lymphoma in textured breas implants. Plast Reconstr Surg. 2019;143(3S):30-40.

8. Agence nationale du médicament et des produits de santé (ANSM): L'ANSM décide, par mesure de précaution, de retirer du marché des implants mammaires macrotexturés et des implants mammaires à surface recouverte de polyuréthane L'ANSM ne recommande pas d'explantation préventive pour les femmes porteuses de ces implants - Communiqué, 4 abril 2019.

9. Allergan Voluntarily Recalls BIOCELL ${ }^{\circledR}$ Textured Breast Implants and Tissue Expanders - Global Action Follows Notification of Updated Safety Information from the U.S. Food and Drug Administration (FDA), 24 July 2019.

10. Torres-Rivero C, Ramos-Gallardo G, Nambo-Lucio MJ, Vaquero-Pérez MM. Primer caso en México y América Latina de linfoma anaplásico de células gigantes en paciente con implantes mamarios Cir plást iberolatinoam. 2016;42(2):175-180.

11. Fernández-Sobrino Y, Cordones-Guerrero JJ, Benítez-Dupin O, Cornejo-Ladrero JI, Lobo-Samper F. Masa palpable como presentación atípica de linfoma anaplásico de células gigantes asociado a implantes mamarios. Cir plást iberolatinoam. 2017;43(2):129-135. 
12. Ebner PJ, Liu A, Gould DJ, Patel KM. Breast implant-associated anaplastic large cell lymphoma, a systematic review and in-depth evaluation of the current understanding. J Surg Oncol. 2019;120(4):573-577.

13. Protocolo clínico para la detección del Linfoma Anaplásico de Células Grandes (LACG) Asociado a Implantes de Mama. Agencia Española de Medicamentos y Productos Sanitarios. Ministerio de Sanidad, Consumo y Bienestar Social. 6 de febrero de 2019.

14. Clemens MW, Horwitz SM. NCCN Consensus Guidelines for the Diagnosis and Management of Breast Implant-Associated Anaplastic Large Cell Lymphoma. Aesthet Surg J. 2017 1;37(3):285-289.

15. Stack A, Levy I. Brentuximab vedotin as monotherapy for unresectable breast implant-associated anaplastic large cell lymphoma. Clin Case Rep.2019;7(5):1003-1006.

16. Clemens MW, Miranda RN. Coming of Age: Breast Implant-Associated Anaplastic Large Cell Lymphoma After 18 Years of Investigation. Clin Plast Surg. 2015;42(4):605-613.

17. Di Napoli A. Achieving Reliable Diagnosis in Late Breast Implant Seromas: From Reactive to Anaplastic Large Cell Lymphoma. Plast Reconstr Surg. 2019;143(3S):15S-22S.
18. Swerdlow SH, Campo E, Harris NL, Jaffe ES, Pileri SA, Stein H, Thiele J (Eds.). World Health Organization Classification of Tumours. WHO Classification of Tumours of Haematopoietic and Lymphoid Tissues. 4th. Ed. IARC, Lyon, 2017.

19. Tevis SE, Hunt KK, Clemens MW. Stepwise En Bloc Resection of Breast Implant-Associated Anaplastic Large Cell Lymphoma with Oncologic Considerations, Aesth Surg J Open Forum. 2019;1(1):1-12.

20. Barnsley GP, Sigurdson LJ, Barnsely SE. Textured Surface breast implants in the prevention of capsular contracture among breast augmentation patients: a metaanalysis of randomized controlled trials. Plast Recontr Surg. 2006;117:2182-2190.

21. Jones P, Mempin M, Hu H, Chowdhury D, Foley M, Cooter R, Adams WP Jr, Vickery K, Deva AK. The functional influence of breast implants outer shell morphology on bacterial attachment and growth. Plast Reconstr Surg. 2018;142(4):837-849.

22. Hanson SE, Hassid VJ, Branch-Brooks C, Liu J, Kadin ME, Miranda R, Butler CE, Clemens MW. Validation of a CD30 Enzyme-Linked Immunosorbant Assay for the Rapid Detection of Breast Implant-Associated Anaplastic Large Cell Lymphoma. Aesthet Surg J. 2018;1:1-5. 
